\title{
Pengaruh Faktor Eksternal Dan Internal Terhadap Keputusan Kredit Oleh Nasabah Pada PT. Pegadaian Manokwari
}

\author{
Yuyun P. Rahayu ${ }^{1}$ \\ ${ }^{1}$ Program Studi Ekonomi Pembangunan, Universitas Papua
}

Received: Desember 2018; Accepted: Januari 2019; Published: Maret 2019

\begin{abstract}
Abstrak
Tujuan dari penelitian ini untuk menganalisis hubungan antara faktor eksternal dan internal nasabah terhadap keputusan pengambilan kredit. Penelitian ini merupakan penelitian asosiatif dengan menggunakan data kuantitatif. Populasi dalam penelitian adalah nasabah PT. Pegadaian Manokwari. Metode pengambilan sampel menggunakan teknik insidental dengan responden yang berjumlah 100 nasabah. Teknik analisis data dalam penelitian ini menggunakan regresi logistik ordinal. Hasil penelitian menunjukkan bahwa variabel independen mempunyai pengaruh secara parsial terhadap keputusan kredit di PT. Pegadaian Kabupaten Manokwari. Variabel yang berpengaruh secara signifikan adalah keseuaian nilai taksiran agunan, kemudahan prosedur dan jenis pekerjaan pagawai baik pegawai negeri maupun pegawai swasta serta rata-rata pengembalian kredit selama dua bulan. Selanjutnya, hasil penelitian menunjukkan bahwa semakin banyak pertimbangan akan menyebabkan peluang keputusan mengambil kredit pada PT. Pegadaian semakin besar dan sebaliknya. Dengan demikian faktor eksternal yaitu agunan dan prosedur dan faktor internal yaitu jenis pekerjaan dan jangka waktu kredit nasabah merupakan faktor yang signifikan pada taraf kepercayaan 95\% mempengaruhi keputusan kredit nasabah pada PT. Pegadaian Manokwari.
\end{abstract}

Kata kunci: keputusan, agunan, kredit, waktu kerja, nasabah

\begin{abstract}
The purpose of this study is to analyze the relationship between external and internal factors on credit decision making by the customers. This is an associative study using quantitative data. Population in this study is the customer of PT. Pegadaian Manokwari. Incidental techniques is used as sampling method with 100 customers as respondents. Data analysis in this study used ordinal logistic regression. The results indicate that the independent variables have partial influence on credit decisions at PT. Pegadaian Manokwari Regency. Variables that have a significant effect are the appropriateness of collateral value, ease of procedure and types of work for both civil servants and private employees as well as the average credit return for two months. Furthermore, the results also indicate that the more considerations will lead to the opportunity for the decision to take credit at PT. Pegadaian are getting higher and vice versa. Thus, collateral and procedures as an external factors and customer's job and credit period as internal factors are significant factors at the $95 \%$ level of confidence affecting the customer's credit decisions at PT. Pegadaian Manokwari.
\end{abstract}

Keywords: decisions, collateral, credit, working time, customers

How to Cite: Rahayu, Y. P. (2019). Pengaruh Faktor Eksternal Dan Internal Terhadap Keputusan Kredit Oleh Nasabah PT. Pegadaian Manokwari. JFRES: Journal of Fiscal and Regional Economy Studies, 2 (1), $69-77$.

\footnotetext{
Corresponding author :

E-mail: yp.rahayu@unipa.ac.id
} 


\section{PENDAHULUAN}

Lembaga keuangan baik bank maupun nonbank memiliki produk kredit yang diberikan kepada nasabah dengan syarat pengembalian yang berbeda-beda. Semakin beragamnya lembaga yang memberikan kredit telah menimbulkan persaingan ketat antar lembaga yang memiliki produk sejenis. Persaingan untuk mencapai target yang telah ditentukan setiap tahun adalah salah satu tantangan yang dihadapi lembaga pemberi kredit disamping peningkatan mutu dan kualitas pelayanan. Setiap calon nasabah akan menjadikan kualitas pelayanan dan keuntungan yang dapat diperoleh sebelum memutuskan untuk meminjam dana pada salah satu lembaga keuangan tersebut.

Penyaluran kredit kepada masyarakat merupakan salah satu fungsi dari lembaga keuangan dan masyarakat yang memutuskan untuk mengambil kredit telah menyepakati syarat-syarat yang diajukan oleh lembaga perkreditan tersebut. Keputusan pengambilan kredit oleh nasabah dipengaruhi banyak faktor yang dapat dikelompokkan menjadi faktor internal dan eksternal. Pengambilan keputusan seorang nasabah atas kebijakan terkait pendanaan melalui hutang perlu mempertimbangkan faktor tersebut. Faktor eksternal nasabah merupakan faktor yang melekat pada pihak yang menyediakan layanan kredit seperti promosi, kualitas, reputasi perusahaan turut mempengaruhi keputusan nasabah. Sementara faktor internal nasabah seperti agunan, tingkat pengembalian kredit, jenis pekerjaan dan pendapatan merupakan pertimbangan dari nasabah dalam memutuskan.

Terdapat dua lingkungan dimana suatu perusahaan melakukan bisnisnya yang disebut lingkungan eksternal dan internal. Industri dan pasar, pesaing dan iklim ekonomi merupakan faktor eksternal yang mempengaruhi pertumbuhan, sedangkan dari sisi faktor internal perusahaan dapat berupa pengusaha kecilnya yang menjalankan manajer (Crijns \& Ooghi, 2000). Menurut Munizu (2010), faktorfaktor yang menunjukkan kinerja suatu usaha dapat dikelompokkan menjadi faktor eksternal dan internal. Faktor eksternal seperti sumber daya manusia, keuangan, teknis produksi dan operasi, serta aspek pasar dan pemasaran. Sedangkan kebijakan pemerintah, aspek sosial budaya dan ekonomi serta peranan lembaga terkait. Kedua faktor ini mempengaruhi kinerja perusahaan dalam hal ini PT. Pegadaian.

Tabel 1. Industri Keuangan Non Bank

\begin{tabular}{llcccccc}
\hline \multirow{2}{*}{ No } & \multicolumn{1}{c}{ Komponen } & \multicolumn{2}{c}{ Konvensional } & \multicolumn{2}{c}{ Syariah } & \multicolumn{2}{c}{ Total } \\
\cline { 3 - 7 } & & $\begin{array}{c}\text { Pelaku } \\
\text { (Unit) }\end{array}$ & $\begin{array}{c}\text { Aset } \\
\text { (Triliun Rp.) }\end{array}$ & $\begin{array}{c}\text { Pelaku } \\
\text { (Unit) }\end{array}$ & $\begin{array}{c}\text { Aset } \\
\text { (Triliun Rp.) }\end{array}$ & $\begin{array}{c}\text { Pelaku } \\
\text { (Unit) }\end{array}$ & $\begin{array}{c}\text { Aset } \\
\text { (Triliun Rp.) }\end{array}$ \\
\hline 1. & LPEI & 1 & 103.27 & 0 & 14.80 & 1 & 118.07 \\
2. & Pergadaian & 85 & 45.45 & 6 & 7.77 & 91 & 53.22 \\
3. & Lembaga Penjamin & 20 & 18.37 & 2 & 1.51 & 22 & 19.87 \\
4. & PT SMF (Persero) & 1 & 17.18 & 0 & 1.93 & 1 & 19.11 \\
5. & PT PNM (Persero) & 1 & 17.26 & 0 & 0.00 & 1 & 17.26 \\
6. & PT Danareksa (Persero) & 1 & 3.42 & 0 & 0.00 & 1 & 3.42 \\
\hline & Total Lembaga & 109 & 204.95 & 8 & 26.00 & 117 & 230.95 \\
\hline
\end{tabular}

Sumber: OJK, 2018

Berdasarkan Tabel 1 diketahui bahwa jumlah pelaku pergadaian adalah yang terbanyak dengan total asset sebesar 53,22 triliun rupiah. Total asset ini adalah kedua terbesar yang berarti bahwa masyarakat masih menaruh kepercayaannya pada lembaga keuangan ini. Dari 91 jumlah pelaku usaha, 90 pelaku usaha lainnya merupakan perusahaan swasta yang baru berkembang sejak tahun 2016 dan tersebar di berbagai wilayah di Indonesia. Namun dari seluruh lembaga keuangan khusus ini, yang terletak di Indonesia Timur hanya dua lembaga swasta di Makassar dan yang yang menjangkau sampai ke Papua adalah perusahaan milik negara yaitu PT.Pegadaian.

PT. Pegadaian pada mulanya berbentuk perum yang kemudian berdasarkan Peraturan Pemerintah Republik Indonesia Nomor 51 Tahun 2011 diubah bentuknya menjadi Perusahaan Perseroan (Persero). Sebagai perusahaan milik pemerintah memberikan penyaluran dana secara kredit atas dasar hukum gadai. Harta berupa emas, perhiasan, elektonik rumah tangga, kamera, alat musik 
dan lain sebagainya dapat digantikan dengan uang jika sepakat dengan persyatan yang ditetapkan (Rachmawati, 2019). Adanya kemudahan dalam bertransaksi dan juga persyaratan tentunya menjadi pilihan utama nasabah untuk mengambil kredit. Namun demikian, banyak faktor yang mempengaruhi selain kemudahan-kemudahan bertransaksi yang ditawarkan seperti kondisi demografi dari nasabah (umur, pendidikan, jenis kelamin, jumlah anak dan asal daerah) juga faktor sosial ekonomi seperti pendapatan, kepemilikan harta benda, jumlah tanggungan dan pekerjaan)

Hasil penelitian sebelumnya menggunakan beberapa faktor yang mempengaruhi penyaluran kredit PT Pegadaian. Rachmawati (2019) menggunakan faktor pendapatan, jumlah nasabah, dan tingkat suku bunga dengan hasil penelitian menyatakan ketiga variabel tersebut secara bersama-sama tidak mempengaruhi penyaluran kredit pada PT. Pegadaian. Sedangkan secara parsial hanya pendapatan dan tingkat suku bunga yang mempengaruhi penyaluran kredit. Sedangkan jumlah nasabah tidak mempengaruhi. Tsalina dan Rachmansyah (2018) meneliti faktor demografi terhadap pengambilan keputusan kredit. Hasil penelitiannya menunjukkan bahwa penghasilan berpengaruh positif, sedangkan umur, profesi dan pendidikan berpengaruh negatif terhadap keputusan pengambilan kredit.

Faktor eksternal adalah faktor dari luar yang mempengaruhi nasabah dalam menentukan kepada lembaga mana akan mengajukan pengambilan kredit. Pada umumnya yang menjadi pertimbangan dari luar adalah hal yang melekat dalam perusahaan atau lembaga kredit seperti persyaratan yang diajukan. Persyaratan pengambilan kredit pada PT. Pegadaian seperti lokasi, agunan, prosedur dan pelayanan. Faktor internal merupakan faktor dari dalam yang menjadi pertimbangan nasabah dalam mengambil kredit seperti faktor demografi dan jangka waktu pengambilan kredit. Dengan penelitian yang menunjukan hubungan faktor internal dan eksternal dan arah hubungannya terhadap pengambilan kredit nasabah di PT. Pegadaian akan menjadi pertimbangan bagi perusahaan penyaluran kredit. Perusahaan akan merujuk pada faktor yang positif dengan pengembalian kredit dari nasabah.

Jika dilihat dari sisi sebaliknya, keputusan pengambilan kredit ada pada nasabah. Menurut
Kotler dan Keller, K (2009), dalam mengambil suatu keputusan pembelian, konsumen akan melalui suatu proses yang terdiri dari 5 tahap, yaitu : 1) Pengenalan kebutuhan, dimana proses pembelian dimulai ketika pembeli mengenali masalah dan kebutuhan; 2) Pencarian informasi, dimana konsumen yang terangsang kebutuhannya akan terdorong untuk mencari informasi yang lebih banyak mengenai produk atau jasa; 3) Evaluasi alternative, dimana konsumen mengolah informasi serta membuat penilaian akhir suatu barang atau jasa; 4) Keputusan pembelian, dimana konsumen akan melakukan pembelian produk atau jasa yang dapat memenuhi kebutuhanya; dan 5) Perilaku pasca pembelian, dimana setelah melakukan pembelian, konsumen mungkin merasakan ketidaksesuaian karena memperhatikan fiturfitur tertentu yang mengganggu atau mendengar hal-hal yang menyenangkan tentang merek lain dan akan mempertimbangkan informasi yang mendukung keputusannya. Berdasarkan uraian latar belakang dan hasil penelitian sebelumnya maka pertanyaan yang dijawab dalam penelitian ini adalah bagaimana hubungan antara faktor eksternal dan internal nasabah PT. Pegadaian Manokwari terhadap keputusan pengambilan kredit?

\section{METODE PENELITIAN}

Penelitian ini dilakukan pada PT. Pegadaian Manokwari dengan menggunakan metode kuantitatif. Populasi dalam penelitian ini adalah semua orang yang menjadi nasabah di PT. Pegadaian yaitu minimal pernah meminjam satu kali di PT. Pegadaian Manokwari. Teknik pengambilan sampel dalam penelitian ini dilakukan dengan teknik Sampling Insidental, teknik penentuan sampel berdasarkan kebetulan, yaitu siapa saja yang menjadi kebetulan/insidental bertemu dengan peneliti dapat digunakan sebagai sampel, bila dipandang orang yang kebetulan ditemui itu cocok sebagai sumber data (Sugiyono, 2009). Mengingat keterbatasan waktu yang ada sehingga dari data yang ada pada PT. Pegadaian Manokwari peneliti mengambil populasi menggunakan data tahun 2013 yang jumlahnya sebanyak 13.406. Perhitungan jumlah sampelnya menggunakan metode Slovin (Umar, 2008) dengan hasil 100 orang responden sampel. 


$$
n=\frac{N}{1+N e 2}
$$

dimana :

$\mathrm{n}=$ Ukuran Sampel

$\mathrm{N}=$ Jumlah Populasi $=13.406$

$\mathrm{e}=$ tingkat kesalahan yang ditorenransi yaitu $10 \%$

$$
n=\frac{13.406}{1+13.406(10 \%)^{2}}=99,26
$$

Sumber data yang diperlukan dalam penelitian ini terdiri dari data primer dan data sekunder. Data Primer merupakan informasi yang dikumpulkan peneliti langsung dari sumbernya. Data primer yang digunakan dalam penelitian ini adalah hasil pengisian kuisioner (angket) oleh responden, yaitu para nasabah PT. Pegadaian Manokwari. Dan data sekunder merupakan data yang disimpulkan dan diterbitkan instansi atau lembaga yang relevan dengan penelitian. Dalam penelitian ini data diperoleh dari PT. Pegadaian Cabang Manokwari.

Jumlah PT. Pegadaian di Kabupaten Manokwari sebanyak sembilan unit yaitu PT. Pedagaian Cabang, Unit Sanggeng, Unit Pasar Wosi, Unit Transito, Unit Pasar Sanggeng, Unit Amban, Unit Kampung Ambon, Unit Kampung Makasar, dan Unit Essau Sesa. Lokasi penelitian berada di 3 (tiga) tempat yaitu di PT. Pegadaian Cabang Manokwari beralamat di jalan Jenderal Sudirman, Unit Kampung Ambon beralamat di jalan Kampung Ambon dan Unit Pasar Wosi beralamat di jalan Pasir Maduraja. Ketiga PT. Pegadaian tersebut memiliki letak yang strategis, dengan kondisi tersebut sehingga banyak masyarakat yang berkunjung dari berbagai kalangan dengan status sosial dan pendidikan yang berbedabeda.

Teknik pengumpulan data yang digunakan pada penelitian ini adalah berdasarkan angket (kuisioner). Kuisioner adalah suatu cara pengumpulan data dengan memberikan atau menyebarkan daftar pertanyaan kepada responden, dengan harapan mereka akan memberikan respon atas daftar pertanyaan tersebut (Umar, 2008).

Metode analisis yang digunakan dalam penelitian ini adalah metode analisis statistik deskriptif. Analisis statistik deskriptif adalah statistik yang digunakan untuk menganalisis data dengan cara mendeskripsikan atau mengambarkan data yang telah terkumpul sebagaimana adanya tanpa bermaksud membuat kesimpulan yang berlaku untuk umum (Sugiyono, 2009). Alat analisis data yang digunakan dalam penelitian ini adalah analisis korelasional. Dalam penelitian ini skala ukur yang digunakan adalah skala ordinal. Regresi Logistik Ordinal kemudian digunakan untuk menentukan hubungan tersebut signifikan atau tidak. Regresi Logistik Ordinal menganalisis variabel dependen yang berskala ordinal dan modelnya merupakan model logit kumulatif. Untuk variabel independen sebanyak $p$, peluang kumulatif dari variabel dependen dengan $j$ kategori didefinisikan sebagai berikut:

$$
P\left(Y i \leq j \mid \boldsymbol{x}_{\boldsymbol{i}}\right)=\frac{\exp \left(\alpha_{j}+\sum_{k=1}^{p} \beta_{k} \boldsymbol{x}_{\boldsymbol{i} \boldsymbol{k}}\right)}{1+\exp \left(\alpha_{j}+\sum_{k=1}^{p} \beta_{k} \boldsymbol{x}_{\boldsymbol{i} \boldsymbol{k}}\right)}
$$

dimana $\boldsymbol{x}_{\boldsymbol{i}}=\left(x_{\boldsymbol{i 1}}, x_{\boldsymbol{i} 2}, \ldots, x_{\boldsymbol{i p}}\right)$ merupakan nilai pengamatan ke-i $(i=1,2,3, \ldots, n)$ dari setiap $\mathrm{p}$ variabel independen. Model regresi logistik ordinal adalah sebagai berikut:

$$
\begin{aligned}
\operatorname{Logit} P\left(Y i \leq j \mid \boldsymbol{x}_{\boldsymbol{i}}\right) & =\ln \left(\frac{P\left(Y i \leq j \mid \boldsymbol{x}_{\boldsymbol{i}}\right)}{1-P\left(Y i \leq j \mid \boldsymbol{x}_{\boldsymbol{i}}\right)}\right) \\
= & \alpha_{j}+\sum_{k=1}^{p} \beta_{k} \boldsymbol{x}_{\boldsymbol{i} \boldsymbol{k}}
\end{aligned}
$$

dimana $\alpha_{j}$ adalah parameter intersep dan $\beta=$ $\left(\beta_{1}, \beta_{2}, \ldots, \beta_{p}\right)$ adalah koefisien regresi.

Untuk pendugaan parameter regresi digunakan transformasi logit dari $P\left(Y i \leq j \mid x_{i}\right)$. Selanjutnya, dilakukan uji $\mathrm{G}$ dan Wald parsial. Statistik uji $G$ menguji peranan variabel independen dalam model secara berdama-sama (likelihood ratio test). Sementara uji Wald parsial menguji koefisien regresi secara parsial dengan membandingkan nilai $\mathrm{W}$ dengan nilai $Z_{\alpha / 2}\left(\right.$ Tolak $\mathrm{H}_{0}$ jika $\mathrm{W}>Z_{\alpha / 2}$ atau $p$-value $<$ $\alpha$.

Odds Ratio $(\psi)$ menjelaskan berapa kali lipat kenaikan/penurunan peluang $\mathrm{Y}=\mathrm{j}$ terhadap $\mathrm{Y}=0$ sebagai referensi, jika nilai variabel independen $(\mathrm{X})$ berubah sebesar nilai tertentu yaitu $\mathrm{x}=\mathrm{a}$ terhadap $\mathrm{x}=\mathrm{b} \quad$ sebagaimana persamaan berikut:

$O R_{j(a, b)}=\psi_{a b}=\frac{P(Y=j \mid x=a) / P(Y=0 \mid x=a)}{P(Y=j \mid x=b) / P(Y=0 \mid x=b)}$

Nilai odds ratio selalu positif. Hubungan antara nilai odds ratio $(\psi)$ dan parameter model $\beta$ adalah: 


$$
\psi_{a b}=\exp (a-b) \beta
$$

dimana jika $\psi<1$ artinya kedua variabel terdapat hubungan negatif dan jika $\psi>$ 1 artinya kedua variabel terdapat hubungan positif.

Gambar 1 menunjukkan kerangka berpikir dimana agunan, prosedur dan pelayanan sebagai faktor eksternal sedangkan jenis pekerjaan, pendapatan, jangka waktu kredit dan lokasi merupakan faktor internal yang mempengaruhi keputusan pengambilan kredit.

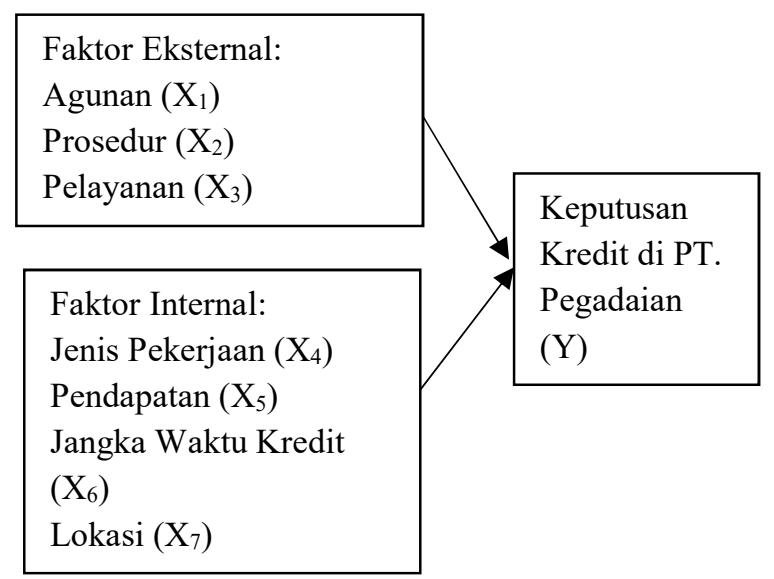

Gambar 1. Kerangka Hubungan Antar Variabel

Berdasarkan rumusan permasalahan dan kerangka berpikir, hipotesis yang dalam penelitian ini adalah sebagai berikut:

1. $\mathrm{H}_{0}$ : Faktor eksternal dan internal tidak berhubungan dengan keputusan pengambilan kredit nasabah pada PT. Pegadaian Manokwari.

2. $\mathrm{H}_{1}$ : Faktor eksternal dan internal berhubungan dengan keputusan pengambilan kredit nasabah pada PT. Pegadaian Manokwari.

Selanjutnya, variabel-variabel yang dipakai dalam penelitian ini secara operasional dapat didefinisikan sebagai berikut:

1. Pengambilan kredit nasabah $(\mathrm{Y})$

Yang menjadi pertimbangan nasabah dalam pengambilan kredit pada PT. Pegadaian terdiri dari agunan, prosedur, dan pelayanan untuk faktor eksternal nasabah dan usia, pendapatan, jangka waktu kredit dan lokasi untuk faktor internal. Pertimbangan nasabah dalam mengambil kredit, sangat penting karena nasabah bermaksud untuk menghindari terjadinya hambatan. Keputusan yang diambil juga dapat menimbulkan efek dan memunculkan masalah pada bidang yang lain. Semakin tinggi skor menunjukkan lebih dari satu pertimbangan nasabah yang mendukung pengambilan kredit pada PT. Pegadaian dan menurunkan peluang pengambilan keputusan kredit oleh nasabah. Indikator keputusan nasabah dalam mengambil kredit sebagai berikut (Suprapto, Maria Mimin, \& Fathoni, 2015):
a. Jarak antara rumah ke lembaga pembiayaan
b. Nilai taksiran atas jaminan yang tinggi
c. Prosedur yang lebih mudah dan cepat
d. Pertimbangan pelayanan karyawan
e. Jangka waktu kredit yang tidak lama

2. Agunan $\left(X_{1}\right)$

Agunan merupakan barang jaminan terdiri atas macam-macam barang bergerak yang telah ditentukan oleh PT. Pegadaian. Indikator yang digunakan pada pertanyaan variabel agunan adalah kesesuaian nilai taksiran dengan barang jaminan yang anda miliki. Jawaban pertanyaan berisi jawaban Ya dan Tidak dengan bobot nilai jawaban yaitu, apabila jawaban Ya diberi skor 1 dan apabila jawaban Tidak diberi skor 0 .

3. Prosedur $\left(\mathrm{X}_{2}\right)$

Prosedur yaitu tata cara atau tahapantahapan yang dilakukan nasabah untuk memperoleh kredit pada PT. Pegadaian. Indikator yang digunakan pada pertanyaan variabel prosedur kecepatan prosedur pencairan dana pinjaman pada PT. Pegadaian. Jawaban pertanyaan berisi jawaban Ya dan Tidak dengan bobot nilai jawaban yaitu, apabila jawaban Ya diberi skor 1 dan apabila jawaban Tidak diberi skor 0 .

4. Pelayanan, $\left(\mathrm{X}_{3}\right)$

Pelayanan adalah setiap kegiatan yang diberikan pihak PT. Pagadaian terhadap masyarakat yang akan maupun yang telah mengambil kredit pada PT. Pegadaian. Indikator yang digunakan pada pertanyaan variabel pelayanan adalah kejelasan informasi tentang tata cara pengambilan kredit gadai ulang. Jawaban pertanyaan berisi jawaban Ya dan Tidak dengan bobot nilai jawaban yaitu, apabila jawaban $\mathrm{Ya}$ diberi skor 1 dan apabila jawaban Tidak diberi skor 0 .

5. Jenis Pekerjaan $\left(\mathrm{X}_{4}\right)$

Jenis pekerjaan nasabah PT. Pegadaian merupakan aktivitas tetap yang dilakukan seseorang untuk memperoleh upah/gaji. Jika tidak memiliki pekerjaan tetap skor- 
nya 0 , pegawai (negeri/swasta) skor-nya 1 dan pedagang skor-nya 2 . Ibu rumah tangga dan mahasiswa, misalnya, tergolong dalam kelompok tidak memiliki pekerjaan tetap.

6. Pendapatan $\left(\mathrm{X}_{5}\right)$

Pendapatan nasabah yang dimaksud adalah penghasilan tetap yang diperoleh selama satu bulan. Besar kecilnya pendapatan didasarkan pada UMR yang berlaku dan diukur dalam satuan rupiah per bulan. Untuk kepentingan analisis, pendapatan dikelompokkan menjadi dua kelompok berdasarkan pendapatan diatas rata-rata atau dibawah rata-rata sampel.

7. Jangka Waktu Kredit $\left(\mathrm{X}_{6}\right)$

Jangka waktu kredit menggunakan satuan bulan. Waktu kredit merupakan periode atau lamanya seseorang mengembalikan pinjaman di PT. Pegadaian.

8. Lokasi $\left(\mathrm{X}_{7}\right)$

Salah satu penentu kesuksesan suatu jasa adalah lokasi. Lokasi erat kaitannya dengan pasar potensial suatu usaha. Lokasi usaha yang tepat diharapkan dapat diperoleh pendapatan yang lebih baik, biaya yang paling rendah dan juga hubungan dengan pelanggan yang cukup baik. Indikator yang digunakan pada pertanyaan variabel lokasi adalah jarak kantor pegadaian dengan rumah. Jawaban pertanyaan berisi jawaban
Ya dan Tidak dengan bobot nilai dari jawaban yaitu, apabila jawaban Ya diberi skor 1 dan apabila jawaban Tidak diberi skor 0 .

Variabel-variabel operasional terangkum dalam Tabel 2.

Tabel 2. Definisi Operasional

\begin{tabular}{clc}
\hline No. & \multicolumn{1}{c}{ Variabel } & $\begin{array}{c}\text { Skala } \\
\text { Variabel }\end{array}$ \\
\hline 1. & Keputusan Pengambilan & Ordinal \\
& Kredit $(\mathrm{Y})$ & \\
2. & Agunan $\left(\mathrm{X}_{1}\right)$ & Nominal \\
3. & Prosedur $\left(\mathrm{X}_{2}\right)$ & Nominal \\
4. & Pelayanan $\left(\mathrm{X}_{3}\right)$ & Nominal \\
5. & Jenis Pekerjaan $\left(\mathrm{X}_{4}\right)$ & Nominal \\
6. & Pendapatan $\left(\mathrm{X}_{5}\right)$ & Ordinal \\
7. & Jangka $\mathrm{Waktu}_{\mathrm{K}} \mathrm{Kredit}\left(\mathrm{X}_{6}\right)$ & Rasio \\
8. & Lokasi $\left(\mathrm{X}_{7}\right)$ & Nominal \\
\hline
\end{tabular}

Sumber: Data primer diolah, 2019

\section{HASIL DAN PEMBAHASAN}

\section{Statistik Deskriptif}

Analisis karakteristik menggambarkan pertimbangan yang digunakan dalam keputusan pengambilan kredit secara umum. Keputusan pengambilan untuk kredit nasabah PT. Pegadaian dilihat dari agunan, prosedur, pelayanan, jenis pekerjaan, pendapatan dan jangka waktu kredit. Distribusi nasabah responden disajikan dalam Tabel 3.

Tabel 3. Faktor-Faktor Yang Mempengaruhi Dan Alasan Keputusan Pengambilan Kredit Pada PT. Pegadaian

\begin{tabular}{|c|c|c|c|c|c|c|}
\hline \multicolumn{2}{|c|}{ Variabel Independen } & \multicolumn{4}{|c|}{ Keputusan Pengambilan Kredit (\%) } & \multirow[t]{2}{*}{$\begin{array}{c}\text { Total } \\
(\%)\end{array}$} \\
\hline & & 1 & 2 & 3 & 4 & \\
\hline \multirow[t]{2}{*}{ Agunan $\left(\mathrm{X}_{1}\right)$} & Tidak (0) & 1.0 & 0.0 & 1.0 & 0.0 & 2.0 \\
\hline & $\mathrm{Ya}(1)$ & 6.0 & 11.0 & 44.0 & 37.0 & 98.0 \\
\hline \multirow[t]{2}{*}{ Prosedur $\left(\mathrm{X}_{2}\right)$} & Tidak (0) & 0.0 & 1.0 & 0.0 & 0.0 & 1.0 \\
\hline & Ya (1) & 7.0 & 10.0 & 45.0 & 37.0 & 99.0 \\
\hline \multirow[t]{2}{*}{ Pelayanan $\left(\mathrm{X}_{3}\right)$} & Tidak (0) & 0.0 & 0.0 & 1.0 & 0.0 & 1.0 \\
\hline & $\mathrm{Ya}(1)$ & 7.0 & 11.0 & 44.0 & 37.0 & 99.0 \\
\hline \multirow[t]{3}{*}{ Jenis Pekerjaan $\left(\mathrm{X}_{4}\right)$} & Tidak ada $(0)$ & 1.0 & 2.0 & 10.0 & 14.0 & 27.0 \\
\hline & Pegawai/Karyawan (1) & 6.0 & 6.0 & 16.0 & 7.0 & 35.0 \\
\hline & Pengusaha (2) & 0.0 & 3.0 & 19.0 & 16.0 & 38.0 \\
\hline \multirow[t]{2}{*}{ Pendapatan $\left(\mathrm{X}_{5}\right)$} & Dibawah rata-rata $(0)$ & 5.0 & 8.0 & 27.0 & 24.0 & 5.0 \\
\hline & Dibawah rata-rata (1) & 2.0 & 3.0 & 18.0 & 13.0 & 2.0 \\
\hline \multirow[t]{4}{*}{ Jangka Waktu Kredit $\left(\mathrm{X}_{6}\right)$} & 1 bulan & 0.0 & 0.0 & 0.0 & 0.0 & 0.0 \\
\hline & 2 bulan & 1.0 & 1.0 & 1.0 & 1.0 & 1.0 \\
\hline & 3 bulan & 8.0 & 8.0 & 8.0 & 8.0 & 8.0 \\
\hline & 4 bulan & 10.0 & 10.0 & 10.0 & 10.0 & 10.0 \\
\hline \multirow[t]{2}{*}{ Lokasi $\left(\mathrm{X}_{7}\right)$} & Jauh $(0)$ & 1.0 & 1.0 & 11.0 & 4.0 & 17.0 \\
\hline & Dekat (1) & 6.0 & 10.0 & 34.0 & 33.0 & 83.0 \\
\hline
\end{tabular}


Uji Goodness of Fit menjelaskan apakah model regresi logistik ordinal yang didapat layak digunakan. Kesesuaian model dengan data ditunjukkan pada Tabel 4. Hipotesis yang digunakan yaitu $\mathrm{H}_{0}$ : model logit layak digunakan $(\alpha>0.05)$ dan $\mathrm{H}_{1}$ : model logit tidak layak digunakan $(\alpha<0.05)$. Nilai Pearson sebesar 74.11 dengan signifikansi $0.980(>0.05)$ dan Deviance sebesar 75.52 dengan signifikansi $0.973(>0.05)$ menunjukkan bahwa model sesuai dengan data empiris dan model layak untuk digunakan.

Tabel 4. Goodness-of-Fit

\begin{tabular}{lccc}
\hline & Chi-Square & df & Sig. \\
\hline Pearson & 74.109 & 101 & .980 \\
Deviance & 75.520 & 101 & .973 \\
\hline
\end{tabular}

Link function: Logit.

Sumber: Data primer diolah, 2019

\section{Uji Keberartian Model}

Pada tahapan ini dibandingkan dua macam model, yaitu model tanpa variabel independen dan model dengan variabel independen. Hipotesis yang diuji adalah $\mathrm{H}_{0}: \beta_{1}=\beta_{2}=\ldots=$ $\beta_{\mathrm{p}}=0$ dan $\mathrm{H}_{\mathrm{a}}$ : minimal salah satu $\beta_{\mathrm{p}} \neq 0$

Tabel 5. Model Fitting Information

\begin{tabular}{lcccc}
\hline \multicolumn{1}{c}{ Model } & $\begin{array}{c}-2 \text { Log } \\
\text { Likelihood }\end{array}$ & $\begin{array}{c}\text { Chi- } \\
\text { Square }\end{array}$ & df & Sig. \\
\hline Intercept Only & 150.836 & & & \\
Final & 123.282 & 27.554 & 10 & .002 \\
\hline Link function: Logit. & & & \\
Sumber: Data primer diolah, 2019 & &
\end{tabular}

Pada Tabel 5 nilai $-2 \log$ Likelihood menunjukkan bahwa jika tidak ada pengaruh variabel independen (intercept only) maka nilai variabel dependen sebesar 150.84. Tetapi dengan pengaruh variabel independen nilainya menjadi 123.28. Nilai Chi-Square atau nilai statistik G sebesar 27.55 signifikan pada taraf nyata $5 \%$ (sig. 0.002). Dengan demikian dapat disimpulkan bahwa terdapat minimal salah satu nilai $\beta_{p} \neq 0$.

Tabel 6. Hasil Output Uji Wald Parsial

\begin{tabular}{|c|c|c|c|c|c|c|}
\hline Variabel Independen & $\beta$ & Wald & Sig & & Keputusan & Kesimpulan \\
\hline Constant 1 & -4.627 & 35.095 & .000 & & Tolak $H_{0}$ & Signifikan \\
\hline Constant 2 & -3.353 & 23.310 & .000 & & Tolak $H_{0}$ & Signifikan \\
\hline Constant 3 & -.816 & 1.864 & .172 & & Gagal Tolak $H_{0}$ & Tidak Signifikan \\
\hline$X_{11}$ & -2.633 & 3.531 & .060 & * & Tolak $H_{0}$ & Signifikan \\
\hline$X_{12}$ & $0^{\mathrm{a}}$ & & & & Gagal Tolak $H_{0}$ & Tidak Signifikan \\
\hline$X_{21}$ & -3.387 & 2.960 & .085 & $*$ & Tolak $H_{0}$ & Signifikan \\
\hline$X_{22}$ & $0^{\mathrm{a}}$ & . & & & Gagal Tolak $H_{0}$ & Tidak Signifikan \\
\hline$X_{31}$ & .912 & .203 & .652 & & Gagal Tolak $H_{0}$ & Tidak Signifikan \\
\hline$X_{32}$ & $0^{\mathrm{a}}$ & . & & & Gagal Tolak $H_{0}$ & Tidak Signifikan \\
\hline$X_{41}$ & -.127 & .055 & .814 & & Gagal Tolak $H_{0}$ & Tidak Signifikan \\
\hline$X_{42}$ & -2.028 & 14.056 & .000 & $* *$ & Tolak $H_{0}$ & Signifikan \\
\hline$X_{43}$ & $0^{\mathrm{a}}$ & & & & Gagal Tolak $H_{0}$ & Tidak Signifikan \\
\hline$X_{51}$ & -.679 & 2.403 & .121 & & Gagal Tolak $H_{0}$ & Tidak Signifikan \\
\hline$X_{52}$ & $0^{\mathrm{a}}$ & . & & & & \\
\hline$X_{61}$ & .670 & 1.168 & .280 & & Gagal Tolak $H_{0}$ & Tidak Signifikan \\
\hline$X_{62}$ & -1.185 & 4.326 & .038 & $* *$ & Tolak $H_{0}$ & Signifikan \\
\hline$X_{63}$ & -.289 & .245 & .621 & & Gagal Tolak $H_{0}$ & Tidak Signifikan \\
\hline$X_{64}$ & $0^{\mathrm{a}}$ & . & . & & Gagal Tolak $H_{0}$ & Tidak Signifikan \\
\hline$X_{71}$ & -.314 & .330 & .565 & & Gagal Tolak $H_{0}$ & Tidak Signifikan \\
\hline$X_{72}$ & $0^{\mathrm{a}}$ & . & . & & Gagal Tolak $H_{0}$ & Tidak Signifikan \\
\hline
\end{tabular}

Keterangan: $*=$ signifikan $90 \%$ dan $* *$ signifikan $95 \%$

Sumber: Data primer diolah, 2019

Hasil pengujian parameter Wald pada tabel 6 menunjukkan hanya variabel independen $X_{11}$, $\mathrm{X}_{21}, \mathrm{X}_{42}$ dan $\mathrm{X}_{62}$ yang mempengaruhi nilai variabel dependen (Y), sedangkan variabel independen sisanya tidak menunjukkan pengaruhnya secara signifikan terhadap variabel dependen. Atau dengan kata lain variabel agunan, prosedur, jenis pekerjaan pegawai dan jangka waktu kredit dua bulan berpengaruh signifikan (pada taraf kepercayaan masingmasing $90 \%$ dan 95\%) terhadap variabel keputusan pengambilan kredit pada PT. Pegadaian.

\section{Model Regresi Logistik Ordinal}

Model logit disusun berdasarkan parameter signifikan yang dihasilkan yang ditunjukkan oleh persamaan berikut: 
$\operatorname{Logit}\left[P\left(Y_{i} \leq 1 \mid x_{i}\right)\right]=-4.637-2.633 X_{1(1)}-$

$3.387 X_{2(1)}-1.483 X_{4(2)}-1.185 X_{6(2)}$

$\operatorname{Logit}\left[P\left(Y_{i} \leq 2 \mid x_{i}\right)\right]=-3.353--2.633 X_{1(1)}-$

$3.387 X_{2(1)}-1.483 X_{4(2)}-1.185 X_{6(2)}$

$\operatorname{Logit}\left[P\left(Y_{i} \leq 3 \mid x_{i}\right)\right]=-0.816-2.633 X_{1(1)}-$

$3.387 X_{2(1)}-1.483 X_{4(2)}-1.185 X_{6(2)}$

Fungsi peluang untuk setiap kategori keputusan

adalah:

1) Peluang keputusan pengambilan kredit karena satu pertimbangan:

$$
\begin{aligned}
\hat{\pi}_{1}\left(X_{i}\right)=\hat{P}\left(Y_{i} \leq\right. & \left.1 \mid x_{i}\right)=\frac{\exp (\log \text { it } 1)}{1+\exp (\text { Logit } 1)} \\
= & 0.000000038
\end{aligned}
$$

2) Peluang keputusan pengambilan kredit karena kurang dari dua pertimbangan:

$$
\begin{aligned}
\hat{\pi}_{1}\left(X_{i}\right)=\hat{P}\left(Y_{i} \leq\right. & \left.2 \mid x_{i}\right) \\
& =\frac{\exp (\text { Logit } 2)}{1+\exp (\text { Logit } 2)} \\
& -\frac{\exp (\text { Logit } 1)}{1+\exp (\text { Logit } 1)} \\
& =0.00000099
\end{aligned}
$$

3) Peluang keputusan pengambilan kredit karena kurang dari tiga pertimbangan:

$$
\begin{aligned}
\hat{\pi}_{1}\left(X_{i}\right)=\hat{P}\left(Y_{i} \leq\right. & \left.3 \mid x_{i}\right) \\
& =\frac{\exp (\text { Logit } 3)}{1+\exp (\text { Logit } 3)} \\
& -\frac{\exp (\text { Logit } 2)}{1+\exp (\text { Logit } 2)} \\
& -\frac{\exp (\text { Logit } 1)}{1+\exp (\text { Logit } 1)} \\
& =0.000001602
\end{aligned}
$$

4) Peluang keputusan pengambilan kredit karena kurang dari empat pertimbangan:

$$
\begin{aligned}
\hat{\pi}_{1}\left(X_{i}\right)=\hat{P}\left(Y_{i} \leq\right. & \left.4 \mid x_{i}\right)=1-\frac{\exp (\text { Logit } 3)}{1+\exp (\text { Logit } 3)} \\
& =0.999998261
\end{aligned}
$$

Nasabah pengusaha yang mengetahui nilai taksiran agunan, kemudahan prosedur dan mengambil kredit paling lama dua bulan mempunyai peluang tertinggi memiliki banyak pertimbangan dalam memutuskan pengambilan kredit pada PT. Pegadaian.

Responden yang tidak memiliki pekerjaan atau merupakan ibu rumah tangga dan mengetahui bahwa terdapat kesesuaian nilai taksiran atas barang jaminannya dan berencana mengembalikan pinjaman setelah sebulan memiliki peluang tertinggi untuk memutuskan mengambil kredit pada PT. Pegadaian dengan besarnya peluang 0.999 . Nilai peluang untuk setiap kombinasi kategori variabel independen terhadap keputusan pengambilan kredit di PT. Pegadaian disajikan dalam Tabel 7.

Berdasarkan Tabel 7, seorang nasabah yang tidak bekerja seperti ibu rumah tangga dan pelajar cenderung memutuskan pengambilan kredit yang dipengaruhi oleh kesesuaian nilai taksiran jaminan. Semakin sesuai taksiran jaminan dan kemudahan prosedur yang ditawarkan PT. Pegadaian maka pertimbangan dalam pengambilan keputusan kredit semakin banyak dan peluang mengambil kredit meningkat berapapun jangka waktu kredit yang diambil. Baik nasabah pegawai maupun pengusaha yang memiliki lebih banyak pertimbangan dalam memutuskan mengambil kredit, peluangnya untuk mengambil kredit akan semakin besar.

Tabel 7. Nilai Peluang Pengambilan Kredit Dengan Berbagai Kombinasi Variabel Independen

\begin{tabular}{cccccccccc}
\hline No & $\mathbf{X}_{\mathbf{1}}$ & $\mathbf{X}_{\mathbf{2}}$ & $\mathbf{X}_{\mathbf{4}}$ & $\mathbf{X}_{\mathbf{6}}$ & ${\text { Prob } \mathbf{Y}_{\mathbf{1}}}$ & ${\text { Prob } \mathbf{Y}_{\mathbf{2}}}$ & Prob $\mathbf{Y}_{\mathbf{3}}$ & ${\text { Prob } \mathbf{Y}_{\mathbf{4}}}$ & $\begin{array}{c}\text { Jumlah Pertimbangan } \\
\text { Pengambilan Kredit }\end{array}$ \\
\hline 1 & 0 & 0 & 0 & 1 & 0.00298 & 0.00760 & 0.10852 & 0.88090 & 4 \\
2 & 0 & 1 & 0 & 1 & 0.00010 & 0.00026 & 0.00419 & 0.99545 & 4 \\
3 & 1 & 0 & 0 & 2 & 0.00007 & 0.00017 & 0.00273 & 0.99704 & 4 \\
4 & 1 & 1 & 0 & 2 & 0.00000 & 0.00001 & 0.00009 & 0.99990 & 4 \\
5 & 0 & 0 & 0 & 3 & 0.00028 & 0.00072 & 0.01148 & 0.98752 & 4 \\
6 & 0 & 1 & 0 & 3 & 0.00001 & 0.00002 & 0.00039 & 0.99957 & 4 \\
\hline
\end{tabular}

Sumber: Data diolah, 2019

\section{Pembahasan}

Nilai koefisien determinasi model regresi logistik ditunjukkan oleh nilai Mc Fadden, Nagelkerke R-Square serta Cox dan Snell.
Kemampuan variabel independen menjelaskan variabel dependen tidak lebih dari $27 \%$. Sementara $73 \%$ sisanya dipengaruhi oleh 
variabel lainnya yang tidak termasuk dalam pengujian model (Tabel 8)

Tabel 8. Pseudo R-Square

\begin{tabular}{ll}
\hline Cox and Snell & .241 \\
\hline Nagelkerke & .267 \\
\hline McFadden & .119 \\
\hline Link function: Logit. &
\end{tabular}

Sumber: Data diolah, 2019

\section{Rasio Odds}

Hasil perhitungan nilai odds ratio berdasarkan keputusan kredit dan kesesuaian nilai taksiran agunan dijelaskan sebagai berikut:

1) Odds ratio dengan satu pertimbangan keputusan kredit $\quad \psi_{1}=\exp ^{-4.627-2.633}=$ 0.0007. Hal ini dapat diartikan bahwa peluang nasabah mengambil kredit di PT. Pegadaian dimana nasabah mempertimbangkan kesesuaian taksiran agunan 0.0007 kali dibanding dengan nasabah yang tidak menilai kesesuaian taksiran agunan.

2) Odds ratio dengan dua pertimbangan keputusan kredit $\quad \psi_{2}=\exp ^{-3.353-2.633}=$ 0.0025 . Hal ini dapat diartikan bahwa peluang nasabah mengambil kredit di PT. Pegadaian dimana nasabah mempertimbangkan kesesuaian taksiran agunan 0.0025 kali dibanding dengan nasabah yang tidak menilai kesesuaian taksiran. agunan.

3) Odds ratio dengan tiga pertimbangan keputusan kredit $\quad \psi_{3}=\exp ^{-0.816-1.185}=$ 0.0318. Hal ini dapat diartikan bahwa peluang nasabah mengambil kredit di PT. Pegadaian dimana nasabah mempertimbangkan kesesuaian taksiran agunan 0.0318 kali dibanding dengan nasabah yang tidak menilai kesesuaian taksiran agunan.

4) Odds ratio dengan empat pertimbangan keputusan kredit $\psi_{4}=\exp ^{-2.633}=0.0719$. Hal ini dapat diartikan bahwa peluang nasabah mengambil kredit di PT. Pegadaian dimana nasabah mempertimbangkan kesesuaian taksiran agunan 0.0719 kali dibanding dengan nasabah yang tidak menilai kesesuaian taksiran agunan.

\section{KESIMPULAN}

Berdasarkan hasil Uji Wald), variabel independen mempunyai pengaruh secara parsial terhadap keputusan kredit di PT. Pegadaian Kabupaten Manokwari. Variabel yang berpengaruh secara signifikan adalah keseuaian nilai taksiran agunan, kemudahan prosedur dan jenis pekerjaan pagawai baik pegawai negeri maupun pegawai swasta serta rata-rata pengembalian kredit selama dua bulan. Semakin banyak pertimbangan akan menyebabkan peluang keputusan mengambil kredit pada PT. Pegadaian semakin besar dan sebaliknya. Dengan demikian, agunan dan prosedur (faktor eksternal) dan jenis pekerjaan dan jangka waktu kredit (faktor internal) merupakan faktor yang signifikan pada taraf kepercayaan 95\% mempengaruhi keputusan pengambilan kredit nasabah pada PT. Pegadaian Manokwari.

\section{DAFTAR PUSTAKA}

Crijns, H., \& Ooghi. (2000). Growth Paths of Medium Sdized Entrepreneurial Companies. De Vlerick School Voor Management, University of Ghent.

Kotler, P., \& Keller, K, L. (2009). Manajemen Pemasaran (13th ed.). Erlangga, Jakarta.

Munizu, M. (2010). Pengaruh Faktor-Faktor Eksternal dan Internal Terhadap Kinerja Usaha Mikro dan Kecil (UMK) di Sulawesi Selatan. Jurnal Manajemen Dan Kewirausahaan, 12(1), pp.33-41. https://doi.org/10.9744/jmk.12.1.pp. 33-41

Otoritas Jasa Keuangan (OJK). (2018). Industri Keuangan Non Bank. Retrieved February 14, 2019, from https://www.ojk. go.id/id/data-dan-statistik/ojk/default.aspx

Rachmawati, R. (2019). Pengaruh Pendapatan, Jumlah Nasabah dan Tingkat Suku Bunga Terhadap Penyaluran Kredit PT Pegadaian Cabang Kabupaten Jember Periode 2013 2017. Jurnal Relasi Stie Mandala Jember, 15(1), 151-174. Sugiyono. (2009). Metode Penelitian Bisnis. Alfabeta, Bandung.

Suprapto, E., Maria Mimin, M., \& Fathoni, A. (2015). Pengaruh Fasilitas Kredit, Suku Bunga, Jangka Waktu Dan Jumlah Kredit Terhadap Keputusan Menggunakan Kredit PD BPR BKK Kota Semarang Cabang Mijen. Journal of Management, 1(1).

Tsalina, A., \& Rachmansyah, Y. (2018). Analisis Pengaruh Literasi Keuangan Dan Faktor Demografi Terhadap Pengambilan Kredit Pada Pt. Columbia Cabang Kudus. Media Ekonomi Dan Manajemen, 33(1), 73-85.https://doi.org/10.24856/MEM.V31

Umar, H. (2008). Metode Penelitian untuk Skripsi dan Tesis Bisnis. PT. Raja Grafindo Persada, Jakarta. 